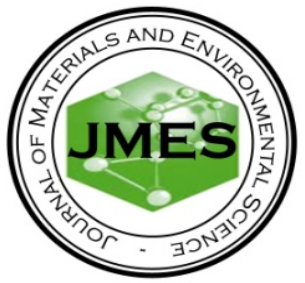

\title{
Residue of manufacture of porcelain stoneware tiles as supplementary material for cement mortars
}

\author{
J. Kreiker $^{1 *}$, R. Gaggino ${ }^{1}$, L. E. Peisino ${ }^{1}$, J. Gonzales Laria ${ }^{1}$ \\ ${ }^{I}$ Experimental Centre for Economic Housing (CEVE) - National Council for Scientific and Technological Research \\ (CONICET) - Economical Housing Association (AVE) -Igualdad 3585 - CP 5000 Córdoba, Argentine
}

Received 11 Aug 2016, Revised 05 Oct 2017 Accepted 13 Oct 2017

Keywords

$\checkmark$ Valorisation of waste,

$\checkmark$ Porcelain stoneware tile,

$\checkmark$ Supplementary materials for cement,

jkreiker@ceve.org.ar ; Tel: +005403514894442

\begin{abstract}
This paper presents the results of the chemical and morphological characterization of a residue produced during the manufacture of the porcelain stoneware tiles, and an alternative for its recycling as cement mortar addition material. The residue studied was provided by a factory in Argentine that produces more than 30 ton/month of dry material, which is currently discarded without a recovery destination. The material was dried in an electric oven at $60^{\circ} \mathrm{C}$ during $180 \mathrm{~min}$ in order to remove surface moisture and break off the agglomerations. The characterization of the residue includes X-Ray fluorescence to determine chemical composition, X-Ray diffraction to determine crystallographic phases, determination of particle size by sieve analysis, specific gravity analysis, and determination of pozzolanic activity by conductivimetric test. Finally, the waste was used as supplementary material for mortar in partial replacement of Portland cement, in a rate of $15 \%$ and $30 \%$ of substitution. The compression strength of mortars was evaluated at 7, 28, 60 and 120 days for probes manufactured using a proportion of cement: sand of 1:3 on weight with water/cement ratio of $0.5 \mathrm{v} / \mathrm{v}$ and in probes with cement without sand. The substitution of $15 \%$ of cement for the waste showed acceptable results of mechanical resistance, but at $30 \%$ the influence was significant with a detrimental effect, however the strengths keeps inside the limits of the norms. We conclude that the waste can be added to mortars up to $15 \%$ without influence on the properties of mortars, adding value to this residue and avoiding the cost of sanitary burial.
\end{abstract}

\section{Introduction}

The porcelain stoneware tiles industry became significant in the last years in Argentine, and won an important place to the traditional ceramic tiles, to a great extent due to its high physical and mechanical characteristics. The final product has the surface polished to increase some mechanical properties and improve its aesthetic [1]. During the operation of polishing, are used silicon carbide as an abrasive and it is cooled by water. In this process is removed approximately $1 \mathrm{~mm}$ of the surfaces as fine powder, which is discarded as Polish Porcelain Residue (PPR). Therefore, the polishing residue is a wet mixture of both the abrasive tool and the porcelain stoneware tile. Manufacturing waste is collected and the water is partially removed by decantation in the station for the treatment of wastewater in the factory, after the residue is disposed in landfill. Therefore, these residues cause both an environmental impact and an increasing of the industrial costs. Unfortunately, because of the presence of some compounds from the polishing process, the waste cannot be recycled by the incorporation newly in the manufacture process, probably due to the decomposition of silicon carbide ( $\mathrm{SiC}$ ) at temperatures higher than $1100^{\circ} \mathrm{C}[2]$, which produces the deformation of the porcelain stoneware tiles so manufactured. As a consequence, this industry generates hundreds of tons each month of residues which are discarded without added value.

The cement industry is considered as highly polluting and several developments have been carried out in order to make this industry more sustainable [3]. In this sense, the use of supplementary materials for cement has been widely recognized as a sustainable alternative and it might be appropriate for reusing the PPR. Only few researches have been done upon the recycling of this material as supplementary material for cement mortars, but the results could be promising $[4,5]$. On the other hand, ashes from industrial and agro industrial processes have been extensively studied as supplementary material for cement mortars [6-7]. It has been demonstrated that 
cement added with these materials have similar or better behavior than normal concrete at ages beyond 28 days, in the most of the cases by the pozzolanic properties of the additive, which are closely related to its morphological properties, being that the more amorphous material has a better pozzolanic behavior [8]. On the other hand, the influence of the waste has also been demonstrated through its particle size which has influence on the rheological properties of the mortar and in their packaging [9, 10]. In Argentine, the addition of pozzolans is according to the IRAM Norm 1654, which establish that the additions cannot decrease the compression strengths of mortars more than $75 \%$ respect to the reference.

The aim of this work was to deepen the study of the chemical and morphological properties of the PPR and the possible use as supplementary material for cement mortars.

\section{Material and Methods}

\subsection{Materials used}

The PPR was provided by ILVA S.A., and comes from the factory placed in Pilar, Buenos Aires. The waste was dried at $60{ }^{\circ} \mathrm{C}$ during $180 \mathrm{~min}$ (constant weight), and then threshed with hand. The cement used was Ordinary Portland Cement (OPC) type CPF 40. The aggregate was grade river sand with fineness modulus of 4.98 determined according IRAM 1505 norms, and specific gravity of 2.65 determined according IRAM 1520 norms. $\mathrm{Ca}(\mathrm{OH})_{2}$ Anhedra (analytical grade) and $\mathrm{H}_{2} \mathrm{O}$ MilliQ quality were used for conductivimetric tests. Cement mortars were made using water from line supply, without purification. Metakaolin (manufacture grade) was provided by Todo Droga. Quartz powder (manufacture grade) was provided by Todo Droga.

\subsection{Physical and chemical analysis}

Physical and chemical analysis: The PPR particle size distribution was determined by gravimetric assay according to IRAM 1505 Norms, using a $0.001 \mathrm{~g}$ precision balance and standard sieves. The specific gravity of PPR was determined according IRAM 1520 Norms. Chemical composition was determined by X-Ray fluorescence (XRF) using a Phillips PW 1400 equipment. The mineralogical analysis of PPR was carried out by X-Ray diffraction (XRD) analyzing the samples prepared in a Phillips X-Pert PRO PW3040/60 diffractometer, with $\mathrm{Cu} \mathrm{K} \alpha \mathrm{X}$-ray radiation, a Siliceous monochromator, at $40 \mathrm{kV}$ and $30 \mathrm{~mA}$, step scan at $0.3^{\circ} / \mathrm{min}$ and step size of $0.02^{\circ} 2 \theta$. t.

\subsection{The pozzolanic activity}

It was determined according to the basic method which consist in evaluating the conductivity of a $\mathrm{Ca}(\mathrm{OH})_{2}$ solution in presence of the pozzolanic material and the evolution of this parameter on time by a period of $600 \mathrm{~h}$ [11]. For this experience $200 \mathrm{~mL}$ of a $\mathrm{Ca}(\mathrm{OH})_{2}$ solution with a conductivity value of approximately $8 \mathrm{mS} / \mathrm{cm}$ was kept at $40 \pm 1{ }^{\circ} \mathrm{C}$ with continuous stirring. Then, $5 \mathrm{~g}$ of the pozzolanic material were added to the solution, and the conductivity was registered over time. The pozzolanic behavior of the material was estimated analyzing the graphic obtained for different materials with different pozzolanic behaviors, being a good parameter the diminishing of the conductivity by the consumption of $\mathrm{Ca}^{2+}$. The graphics were made with the Microcal Origin Pro 8.0 Software, and the curves of conductivity were fitted with a simple exponential equation in a simple qualitative analysis. The pozzolanic behavior of PPR was compared whit metakaolin and powder of quartz, as pozzolanic and no-pozzolanic references respectively.

\subsection{Compressive strength}

The tests were carried out according IRAM 1622 Norms in a Universal Press Machine of 30 Ton $0.5 \mathrm{MPa} / \mathrm{s}$, registering for each specimen the maximum sustained load. Prismatic test specimens of $4 \times 4 \times 16 \mathrm{~cm}$ were made by replacing $15 \%$ and $30 \%$ of cement with PPR in probes A. A binder: sand proportion of $1: 3$ on weight and a water/cement $(\mathrm{W} / \mathrm{C})$ rate of 0.5 , was used in mortar probes $\mathrm{B}$, in which cement was replaced by $15 \%$ and $30 \%$ of PPR. The reference pastes without PPR were named Probe A and Probe B, respectively. The specimens were compacted using a vibration table, and then covered overnight with a wet plastic sheet. After twenty-four hours, the probes were removed from their molds, and cured in water at $20^{\circ} \mathrm{C}$ until tests at $14,28,60$ and 120 days. We tested six specimens at each age and the average value was reported. The analysis of variance (ANOVA) and LSD Test were used in order to determine the statics significance between the different treatments, using for this the software INFOSTAT 2014e.

\section{Results and discussion}

Physical and Chemical analysis: The analysis of particle size of PPR is shown in Figure 1. The 90\% of the particles are under $300 \mu \mathrm{m}$. The value determined of specific gravity was $2.27 \mathrm{~g} / \mathrm{cm}^{3}$, and correspond to the average of six determinations with a $\mathrm{CV}<5 \%$. 


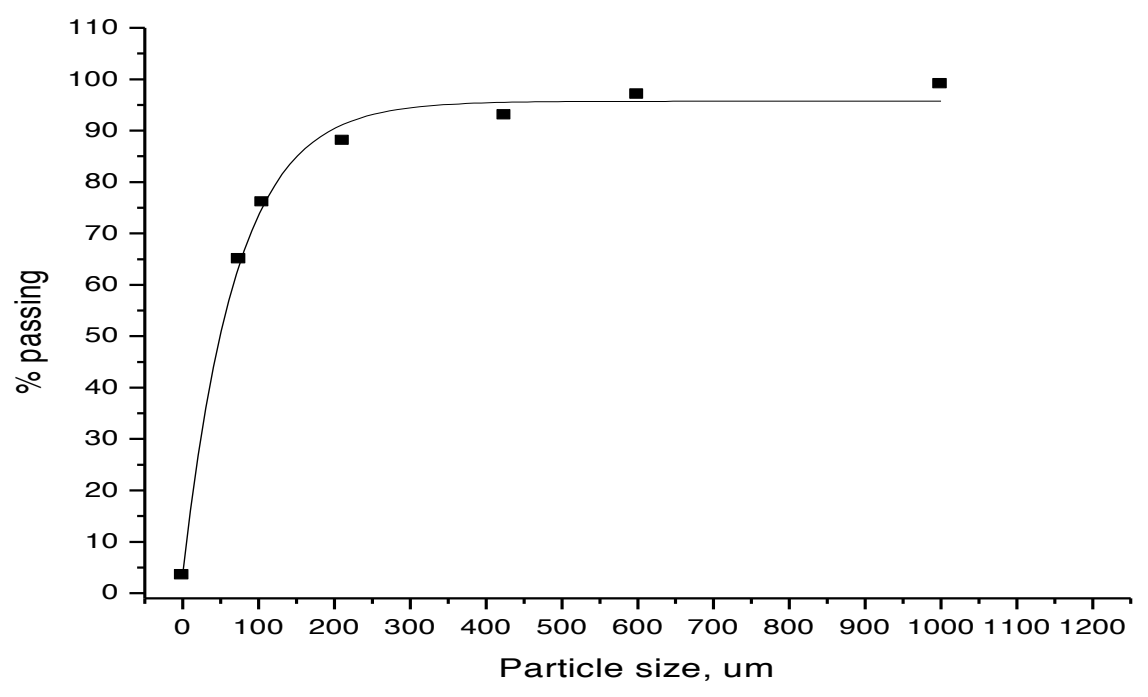

Figure 1: Particle size distribution of PPR, determined by gravimetric test

The chemical analysis of PPR is shown in Table 1. The sum of silica, aluminum, and iron oxides contents is higher than $70 \%$ of the total, corresponding to a type N pozzolan, according to ASTM-C618 Norms, besides the high content of $\mathrm{SiO}_{2}$ could be a good signal of pozzolanic properties. The content of alkali oxides $\mathrm{K}_{2} \mathrm{O}$ and $\mathrm{Na}_{2} \mathrm{O}$ is higher than $1.5 \%$ permitted by norm, making it not advisable for some applications, because of the undesirable alkali-aggregate reaction in cement mortars $[12,13]$. The content of $\mathrm{MgO}$ is low which suggest that there are not expansive reactions in the mortars [14]. The presence of $\mathrm{ZrO}_{2}$ is due to this compound is added during the manufacture to whiten the porcelain stoneware tiles.

Table1: Chemical analysis of PPR

\begin{tabular}{|c|c|c|c|c|c|c|c|c|c|}
\hline $\mathbf{S i O}_{2}$ & $\mathbf{A l}_{2} \mathbf{O}_{3}$ & $\mathbf{C a O}$ & $\mathbf{F e}_{2} \mathbf{O}_{3}$ & $\mathbf{N a}_{2} \mathbf{O}$ & $\mathbf{K}_{2} \mathbf{O}$ & $\mathbf{M g O}$ & $\mathbf{T i O}_{2}$ & $\mathbf{Z n O}$ & $\mathbf{Z r O}_{2}$ \\
\hline 72.5 & 14.3 & 2.0 & 6.2 & 1.8 & 2.4 & 0.9 & 0.5 & 0.3 & 0.8 \\
\hline
\end{tabular}

The Figure 2 shows the X-Ray analysis of PPR. There are significant quantities of crystal-phases as Quartz (Q), and the comparison with spectra of the library made with the software PANalytical X'Pert Highscore shows a high coincidence with this compound. The other components determined by X-Ray Fluorescence did not present crystalline phases; either be in small amount or be in amorphous phases.

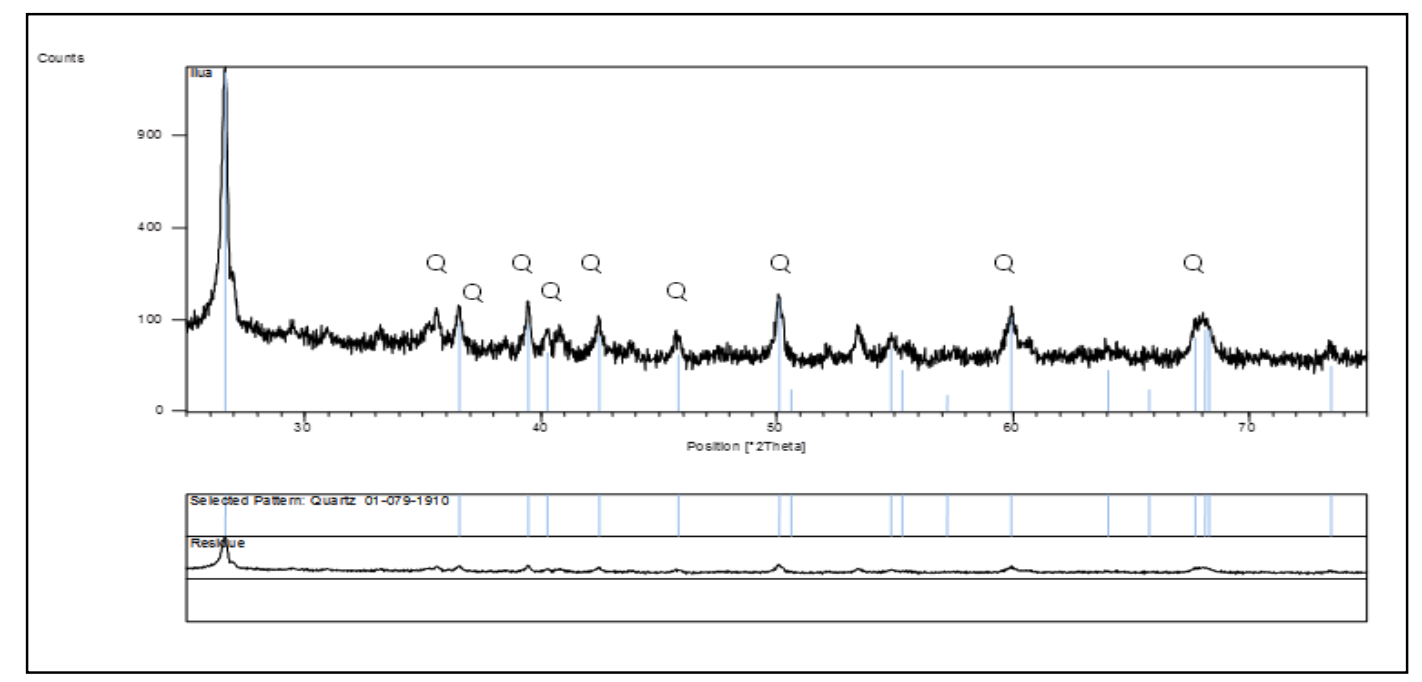

Figure 2: X-Ray diffraction of PPR 
The pozzolanic activity: was determined by the conductivimetric test by the measurement of the reactivity in an unsaturated lime solution at $40^{\circ} \mathrm{C}$. The Figure 3 shows the decreasing of conductivity of the lime solution when the materials were added. The metakaolin showed a strong decrease from $9 \mathrm{mS} / \mathrm{cm}$ up to $1 \mathrm{mS} / \mathrm{cm}$ in the conductivity which is consistent with a very good pozzolanic behavior. The PPR showed an important decrease in the conductivity, which could mean a good pozzolanic behavior, but is important to highlight that this decrease in the conductivity value is only a clue of the pozzolanicity of the material, because the amount of Calcium ions is too small in a solution of $9 \mathrm{mS} / \mathrm{cm}$, compared with the potential reactants in $5 \mathrm{~g}$ of material added. Therefore, the little amount of amorphous $\mathrm{SiO}_{2}$ could be the responsible of the consumption of $\mathrm{Ca}^{2+}$ and so the pozzolanic reaction. In this way might be a big amount of $\mathrm{SiO}_{2}$ in crystalline phases which is not a pozzolanic material and so non-reactive towards Calcium ions as was reported by other authors [15]. On the other hand, the quartz powder showed a little decrease in the conductivity, which is according to a bad pozzolanic material, and the consumption of $\mathrm{Ca}^{2+}$ is similar to the blank solution, where the decreasing of the conductivity is due to the consumption of $\mathrm{CO}_{2}$ from the atmosphere to give $\mathrm{CaCO}_{3}$ in the carbonation reaction, but it is not significant respect to the effect caused by the material added.

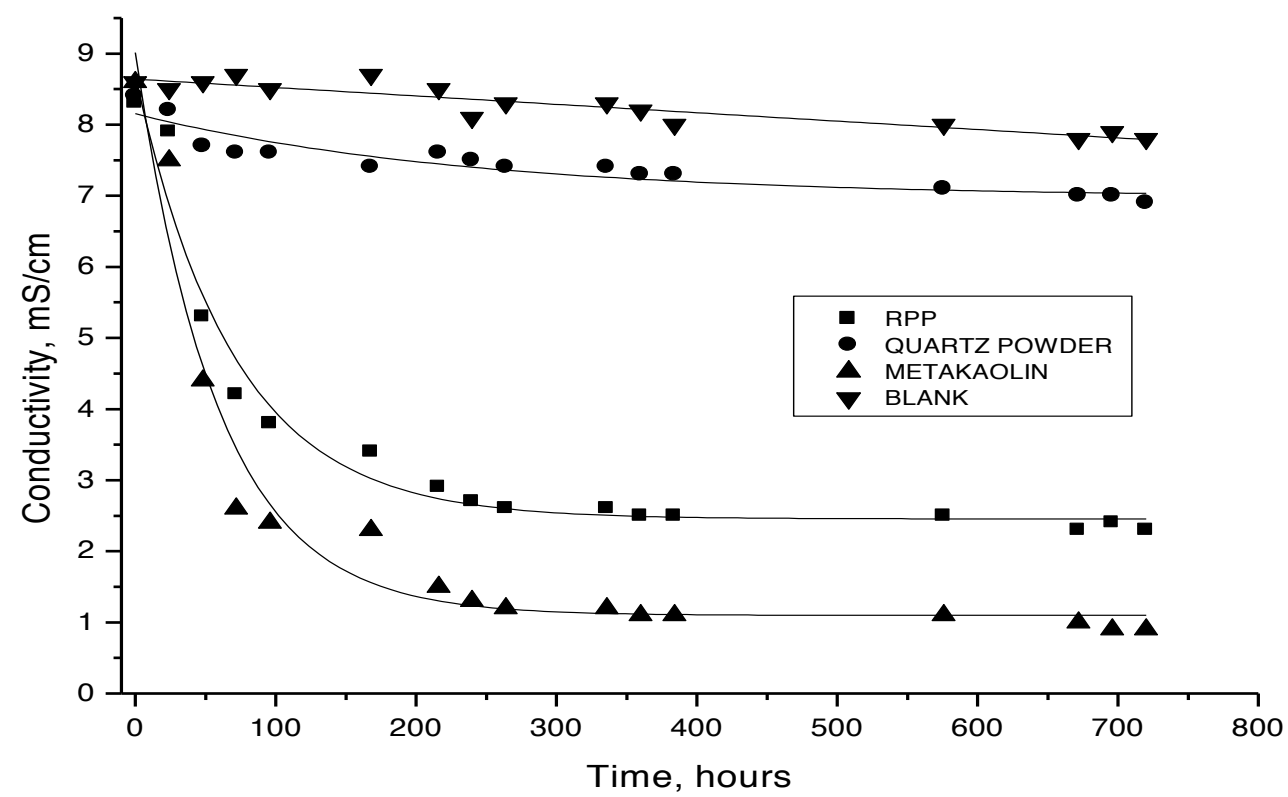

Figure 3: Conductivimetric assays of pozzolanic materials in lime solution.

Compressive strength tests: The Table 2 shows the results of compressive strength tests for probes made with PPR. The values correspond to the average of 6 measurements by entry with the variance coefficient $\%$ in brackets, applying Grubbs contrast to discard outlier points. The LSD tests were calculated with software INFOSTAT 2014e, in the analysis of variance ANOVA. The comparison corresponds to the different specimens A and B tested at different ages. Similar letters mean similar behaviors for different treatments.

Table 2: Compressive strength tests at different ages

\begin{tabular}{|r|c|c|c|c|c|}
\hline \multirow{2}{*}{ Treatment } & \multirow{2}{*}{ PPR \% } & \multicolumn{5}{|c|}{ Compressive strength [MPa] (CV\%) at different ages (days) } \\
\cline { 3 - 6 } & & $\mathbf{1 4}$ & $\mathbf{2 8}$ & $\mathbf{6 0}$ & $\mathbf{1 2 0}$ \\
\hline Probe-A & 0 & $28.5(4)^{\mathrm{a}}$ & $31.2(2)^{\mathrm{a}}$ & $33.0(2.5)^{\mathrm{a}}$ & $33.8(2)^{\mathrm{a}}$ \\
\hline PPR-A-15 & 15 & $26.8(6)^{\mathrm{b}}$ & $29.9(3)^{\mathrm{b}}$ & $32.4(4)^{\mathrm{a}}$ & $33.3(3)^{\mathrm{a}}$ \\
\hline PPR-A-30 & 30 & $24.3(5)^{\mathrm{c}}$ & $28.1(4)^{\mathrm{c}}$ & $29.1(4)^{\mathrm{b}}$ & $30.4(2)^{\mathrm{b}}$ \\
\hline Probe-B & 0 & $20.0(6)^{\mathrm{d}}$ & $24.6(3)^{\mathrm{d}}$ & $27.2(5)^{\mathrm{c}}$ & $28.5(4)^{\mathrm{c}}$ \\
\hline PPR-B-15 & 15 & $18.2(4)^{\mathrm{e}}$ & $23.5(5)^{\mathrm{e}}$ & $26.4(3)^{\mathrm{c}}$ & $27.8(2)^{\mathrm{c}}$ \\
\hline PPR-B-30 & 30 & $16.5(5)^{\mathrm{f}}$ & $19.1(3)^{\mathrm{f}}$ & $20.2(4)^{\mathrm{d}}$ & $21.9(5)^{\mathrm{d}}$ \\
\hline
\end{tabular}

The graphics of Probes-A are shown in Figure 4. It shows a similar behavior for Probe-A (reference paste) and PPR-A-15 with $15 \%$ of PPR. The little difference is not significant at ages later than 60 days where the LSD test shows similar values at $95 \%$ of confidence interval. The PPR-A-30 shows compression strength lower than the reference. In all the cases the values are higher than $75 \%$ respect to the reference, complying with the 
Argentinean Norm for pozzolanic additions, in which case even if it did not improve the properties of the specimens did not produce a significant reduction in the compression strength of probes. For Probes-B, showed in the Figure 5, the behavior is similar, at older ages than 60 days the paste with an addition of $15 \%$ of PPR was similar to the reference, which was demonstrated with the results of LSD test. On the other hand, the PPR-B-30 showed a different behavior and at this rate of substitution of cement the detrimental effect was significant. Despite of this effect, the mortar with PPR at $30 \%$ keep inside the limit established by the norm with compression strength higher than $75 \%$ respect to reference, and the RPP can be used as supplementary material for cement mortars, Figure 5.
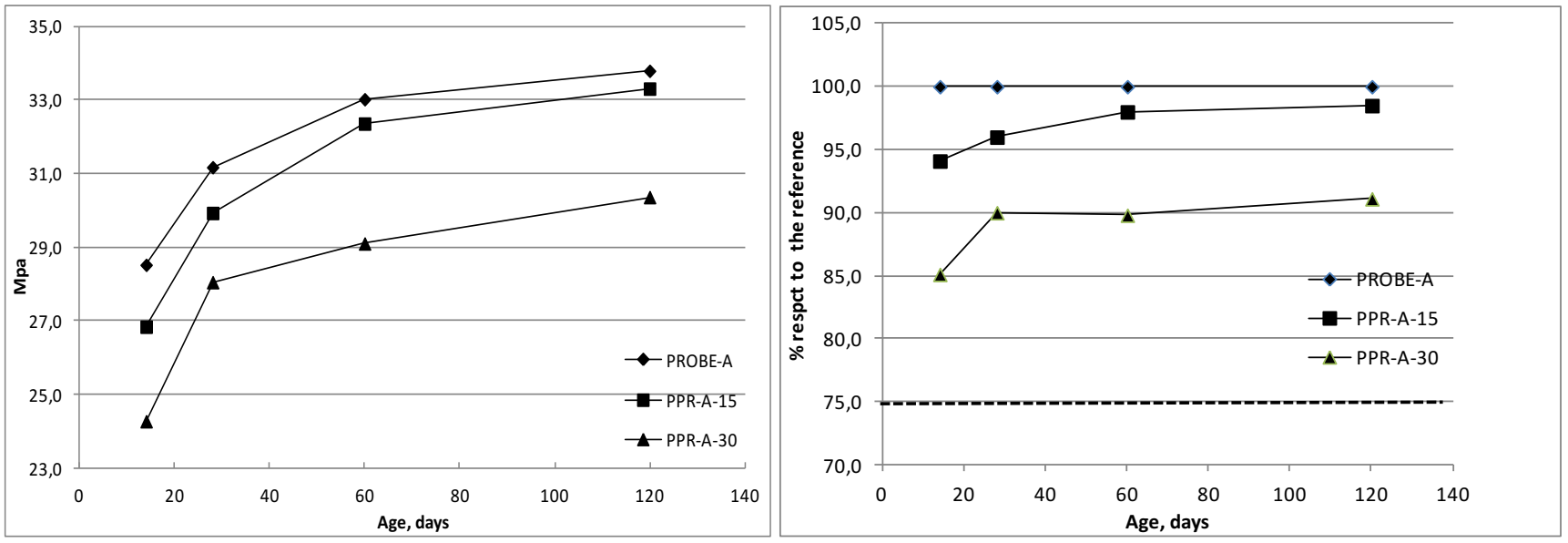

Figure 4: Compressive strength graphics and limits of Argentinean norm for cement pastes
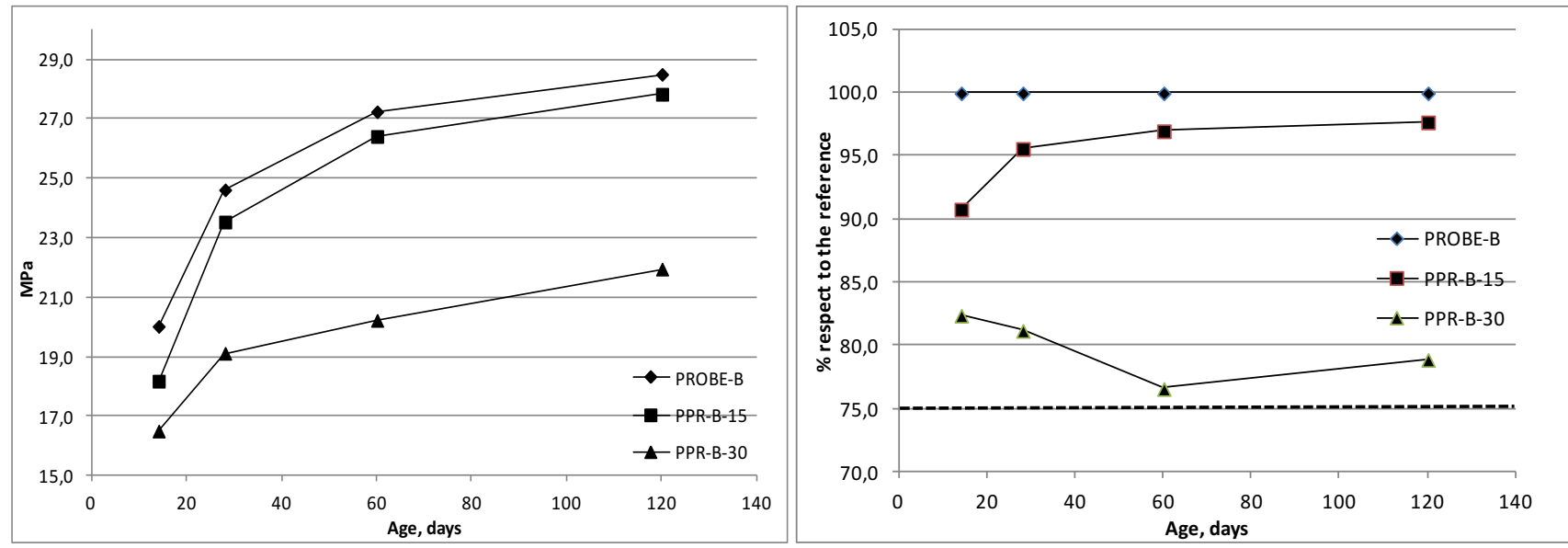

Figure 5: Compressive strengths graphics and limits of Argentinean norm for cement mortar pastes.

\section{Conclusion}

We recommend the use of RPP as supplementary material for cement mortars, replacing the Portland cement up to $15 \%$ for the waste material, which produced no detrimental effects in compression strength in mortars and neither in cement pastes.

The replacement of Portland cements up to $30 \%$ for the waste material could be used in the cement mortar, but we recommend the using in building not subject to structural loads.

The recycling of this waste could bring important benefits to the porcelain stoneware tile industry by adding value to its wastes and saving money spent on the final disposal.

The application proposed for this waste contributes with the reduction in cement consumption making more sustainable the construction industry and diminishing the environmental pollution.

Further studies on the properties of mortars with RPP are being carried out in order to extend the proposal uses.

Acknowledgments-The authors wish to thank to the Experimental Center for Economical Housing (CEVE), and the National Council of Scientific and Technological Research (CONICET). We are grateful to ILVA S.A. Company for the supply of waste material. 


\section{References}

1. L. Esposito Tucci A., Am. Ceram. Soc. Bull, 79 (5) (2000) 59.

2. M. Schneider, M. Romer, M. Tschudin, H. Bolio, Cem. Concr. Res, 41 (2011) 642.

3. N. Muller, J. Harnish, A blueprint for a climate friendly cement industry. Gland: WWF Lafarge Conservation Partnership (2008).

4. F. Pelisser, L. R. Steiner, A. M. Bernardin, Environ. Sci. Technol., 46 (2012) 2368.

5. E. Rambaldi, L. Esposito, A. Tucci, G. Timellini, J. Eur. Ceram. Soc., 27 (2007) 3509.

6. K. E. Hassan, L. G. Cabrera, R. S. Maliehe, Cem. Concr. Compos., 22 (2000) 267.

7 O. Obinna, B. Nemkumar, Cem. Concr. Compos., 68 (2016) 96.

8. E. Villar-Cociña, E. Valencia Morales, S. Santos, Jr. H. Savastano, M. Frias, Cem. Concr. Compos., 33 (2011) 68.

9. P. Chindaprasirt, S. Homwuttiwong, V. Sirivivatnanon, Cem. Concr. Res, 34 (2004) 1087.

10 J. Dengwu, S. Caijun, y. Qiang, A. Xiaopeng, L. Huang, Cem. Concr. Compos., 83 (2017) 146.

11. M. P. Luxan, F. Madruga, J. Saavedra, Cem. Concr. Res, 19 (1989) 63.

12. J. E. Gillot, J. Mater. Civ. Eng, 4 (1995) 278.

13. H. F. Taylor, Cement Chemistry, Ed. London Thomas Telford ISBN : (1997).

14. G. M. Idorn, Cem. Concr. Res, 22(6) (1992) 1039.

15. J. F. Martirena-Hernandez, S. Betancourt-Rodriguez, B. Middendorf, A. Rubio, J. Martinez-Fernandez, J. Machado Lopez, R. Gonzales-Lopez, Materiales de Construcción, 50 (260) (2000) 71.

\section{Norms}

ASTM-C618 12a. American Society for Testing and Materials Standard Specification for Coal Fly Ash and Raw or Calcined Natural Pozzolan for Use in Concrete. ASTM-C618. Book ASTM Stand. 04.02 (1997) 294-296.

IRAM 1505:2005. Instituto Argentino de Normalización y Certificación. Agregados. Análisis granulométrico.

IRAM 1520:2002. Instituto Argentino de Normalización y Certificación. Agregados finos. Métodos de laboratorio para la determinación de la densidad relativa real, de la densidad relativa aparente y de la absorción de agua.

IRAM 1622:2006. Instituto Argentino de Normalización y Certificación. Cemento Portland Métodos de determinación de las resistencias a compresión y flexión.

IRAM 1654:1968. Instituto Argentino de Normalización y Certificación. Puzolanas. Métodos de ensayos generales

IRAM 50000:2010. Instituto Argentino de Normalización y Certificación. Cemento. Cemento para uso general. Composición, características. Evaluación de la conformidad y condiciones de recepción.

(2018) ; http://www.jmaterenvironsci.com 